\title{
Palliative treatment of patients with inoperable locally advanced, recurrent or metastatic head and neck squamous cell cancer, using a low-dose and personalized chemotherapeutic regimen
}

\author{
ROHIT BISHNOI ${ }^{1}$, JEFFERY BENNETT $^{2}$ and DAVID N. REISMAN ${ }^{3}$ \\ ${ }^{1}$ Division of Hospital Medicine, Department of Medicine; ${ }^{2}$ Department of Radiology; \\ ${ }^{3}$ Division of Hematology and Oncology, Department of Medicine, University of Florida, Gainesville, FL 32610, USA
}

Received August 8, 2016; Accepted January 13, 2017

DOI: $10.3892 / \mathrm{ol} .2017 .6068$

\begin{abstract}
Inoperable or metastatic head and neck squamous cell cancer (HNSCC) is known to be associated with a poor patient prognosis. First line therapies include a Taxol, platinum-based antineoplastic and fluorouracil (FU) treatment regimen (TPF) or a platinum-based antineoplastic, FU and EGFR inhibitor treatment regimen (PFE). The toxicity of these regimens is one of the major limiting factors, particularly for palliative treatment. The present study is a retrospective study of 15 patients with HNSCC, where the treatment goal was palliative. Of the 15 patients, 8 received a TPF, while 7 received a PFE. A total of 129 treatment cycles were administered with a median of 9 cycles (range, 3-14). Chemotherapy began with low doses and was subsequently titrated up based on tolerance and response. Positive responses were noted with the lower doses compared with the conventional doses, and maximal doses were not required. The median dose of cisplatin, paclitaxel and 5-FU administered was $40 \mathrm{mg} / \mathrm{m}^{2}, 80 \mathrm{mg} / \mathrm{m}^{2}$ and $360 \mathrm{mg} / \mathrm{m}^{2} /$ day for 5 days, respectively. Cetuximab was used at a standard dose. At the initial follow-up (mean, 64 days; 3 cycles), a
\end{abstract}

Correspondence to: Dr David N. Reisman, Division of Hematology and Oncology, Department of Medicine, University of Florida, 2000 Archer Road, Gainesville, FL 32610, USA

E-mail: dnreisman@ufl.edu

Abbreviations: HNSCC, metastatic head and neck squamous cell cancer; LA/R/M, locally advanced, recurrent or metastatic; EGFR, epidermal growth factor receptor; FU, fluorouracil; TPF, Taxol, platinum-based antineoplastic and FU treatment regimen; PFE, platinum-based antineoplastic, FU and EGFR inhibitor treatment regimen; OS, overall survival; PFS, progression-free survival; QOL, quality of life; CR, complete response; PR, partial response; $\mathrm{SD}$, stable disease; $\mathrm{PD}$, progressive disease; $\mathrm{nCR}$, near complete response; DCR, disease control rate; ORR, overall response rate; pCR, pathologic complete response; TTP, time to tumor progression

Key words: low-dose chemotherapy, recurrent HNSCC, palliative chemotherapy, patient customized chemotherapy
$100 \%$ disease control rate (DCR) and $80 \%$ overall response rate (ORR) was achieved. A positive response, $60 \%$ DCR and $60 \%$ ORR, was maintained until the late stages of the study (mean, 217 days; 9 cycles). Following termination of chemotherapy after $>9$ cycles, 4 patients remained disease free for $\sim 1$ year. A total of 3 patients exhibited a pathologic complete response despite radiologically exhibiting residual disease. The median progression-free survival time was 10.03 months and the overall survival time was 15.77 months. The only grade 3 hematologic toxicity noted was neutropenia in $3(20 \%)$ patients. Grade 3 vomiting was noted in $1(6.67 \%)$ patient and grade 3 stomatitis was noted in 1 (6.67\%) patient. Due to low toxicity patients exhibited improved tolerance to this approach, particularly in terms of palliative care. Furthermore, these results are in contrast to the axiom that increased doses are more effective.

\section{Introduction}

In the USA head and neck squamous cell cancer (HNSCC) constitutes 3\% of all malignancies (1). A total of $\sim 60,000$ American people develop HNSCC annually and $\sim 12,000$ people succumb to the disease every year (1). HNSCC frequently exhibits reoccurrence, and a number of cases are diagnosed in the advanced and incurable stage (2-5). The median survival time for patients with inoperable locally advanced, recurrent or metastatic (LA/R/M) HNSCC remains dismal $(4,6)$. Treatment of this group of patients with HNSCC has been challenging and is still in development (5,7). Due to the superiority of the Taxol, platinum-based antineoplastic and fluorouracil (FU) treatment regimen (TPF) compared with other combinations, this regimen is used as the first line treatment of HNSCC, particularly in induction chemotherapy (8-10). The addition of epidermal growth factor receptor (EGFR) inhibitors has also presented a significant survival advantage in the treatment of LA/R/M HNSCC and are currently used as a first line therapy in combination with platinum-based antineoplastics, 5-FU or taxanes (11-14).

In the treatment of patients with advanced HNSCC, a number of patients are reluctant to undergo chemotherapy unless they are likely to receive no side effects. As these patients have frequently undergone disfiguring 
HNSCC surgery, and suffer from the side effects of chemotherapy/radiotherapy, including dry mouth and loss of taste, it is not unreasonable to balance further therapy with the maintenance of quality of life (QOL), given that these patients are terminally ill (15).

The principle axiom of chemotherapy has been that the highest tolerated (acceptable percentage of grade 3 and 4 toxicities) is the preferred regimen to use $(16,17)$. Therefore, the degree of grade 3 and 4 toxicity observed is frequently a limitation to the accepted chemotherapeutic regimen, particularly as this limits the number of cycles that may be administered. However, in contrast to this axiom and in response to the will of the patient for an improved QOL, alternative regimens with decreased chemotherapeutic doses have been investigated as alternative, less toxic treatments offering an improved QOL, particularly in palliative care $(18,19)$. Platinum-based antineoplastics, taxanes and 5-FU have been studied at various dosages, and in various combinations and schedules, from weekly to every 3 weeks, and these studies have demonstrated a decreased toxicity profile with varying response rates (18-23). Varying degrees of success using low dose regimens indicate that low doses may be effective, particularly if drugs are used in combination (19). As each individual and tumor has a distinct sensitivity to these drugs, with respect to response and toxicity, it is evident that no single treatment regimen may be applicable to all patients (19,24-27). Therefore, the present study reports the administration of decreased doses of a TPF and platinum-based antineoplastic, FU and EGFR inhibitor treatment regimen (PFE), where severe and moderate toxicity was unlikely to occur. The doses were subsequently titrated up to achieve the highest dose with the fewest side effects. The present study aimed to determine whether an increased number of treatment cycles at decreased doses equates to improved response and survival (28).

\section{Materials and methods}

Ethical approval and consent to participate. This study was conducted following ethical approval from the Institution Review Board (IRB) of the University of Florida (Gainesville, FL, USA). A full waiver of informed consent was obtained from the IRB and no patient consent was required for the present study (study approval reference no. IRB201500105).

Study group. The present study presents the retrospective analysis of 15 patients who were treated at the University of Florida Hospital (Gainesville, FL, USA) between November 2012 and December 2015. The patient population consisted of $86.67 \%$ males and $13.33 \%$ females, with a median age of 66.4 years (range, 50.9-79.4 years). A total of $80 \%$ of patients exhibited recurrent disease and $20 \%$ of patients were newly diagnosed. A total of $1 / 6$ of the newly diagnosed patients initially underwent radiation treatment $<6$ months prior to starting systemic palliative chemotherapy. A total of $86.67 \%$ of the patients had previously received radiotherapy, $53.33 \%$ had previously received chemotherapy and $40.00 \%$ had previously received surgical treatment. A total of $73.33 \%$ of patients exhibited loco-regional advanced disease, while $26.67 \%$ of patients exhibited metastatic disease at presentation. Due to their disease status, these patients were referred for palliative treatment and QOL was an important factor in decision-making. Detailed patient characteristics are listed in Table I.

Treatment. Patients in the present study were treated with decreased doses of taxanes, platinum-based antineoplastics, 5-FU and EFGR inhibitors. These drugs were provided by the pharmacy of the University of Florida. Of these 15 patients, 8 patients received a TPF and 7 received a PFE. These 15 patients received a combined total of 129 treatment cycles with a median of 9 cycles (range, 3-14). The physician who administered the treatment recommended the chemotherapeutic protocol based on individual patient characteristics, clinical assessment, previous treatments and other comorbidities. Dosages were regularly reassessed and adjusted based on follow-up clinical assessments, response and tolerability, with an objective to providing a positive response and improved QOL.

The taxanes paclitaxel $\left(80 \mathrm{mg} / \mathrm{m}^{2}\right)$, nab-paclitaxel $\left(90 \mathrm{mg} / \mathrm{m}^{2}\right)$ and docetaxel $\left(80 \mathrm{mg} / \mathrm{m}^{2}\right)$ were administered as a split course regimen to minimize the toxicity associated with 3 -weekly dosing. Therefore, these drugs were administered on day 1 and day 8 of a 3 -week cycle. 5-FU $\left(360 \mathrm{mg} / \mathrm{m}^{2} / \mathrm{day}\right)$ was administered on day 1 of the cycle for a continuous $120 \mathrm{~h}$ instead of the standard $96 \mathrm{~h}$ infusion to mitigate toxicity $(9,29)$. Capecitabine at $700 \mathrm{mg} / \mathrm{m}^{2}$ twice daily was infrequently substituted (typically in later cycles) in place of 5-FU in case the patient was not able to receive 5-FU due to issues, including port malfunction. In the platinum-based antineoplastic group, cisplatin was administered on day 1 of a 3-week cycle at $40 \mathrm{mg} / \mathrm{m}^{2}$. Carboplatin was infused on day 1 of a 3 -week cycle to give an area under the curve of $\sim 3.5$, when patients demonstrated cisplatin toxicity necessitating a drug change. In the EFGR inhibitor group, cetuximab was used according to the recommended doses of $400 \mathrm{mg} / \mathrm{m}^{2}$ on day 1 (single treatment) followed by $250 \mathrm{mg} / \mathrm{m}^{2}$ every week. When severe cetuximab hypersensivity was encountered, panitumumab was used on day 1 of every 3 -week cycle and the dose was titrated to achieve <grade 3 toxicity. Table II presents the average, median and range of the most commonly used drugs compared with the recommended doses $(9,11,12,14,30)$.

Analysis. Performance status was measured using the Eastern Cooperative Oncology Group scale (31). Toxicity and adverse effects were graded according to the National Cancer Institute Common Terminology Criteria for Adverse Events (CTCAE; version 3.0) (32). Response to treatment was evaluated using various radiological studies, including computed tomography scans, magnetic resonance imaging and positron emission tomography scans. The tumor volumes were calculated using the Visage Picture Archiving and Communication Systems. The outline of the enhancing portion of the tumor is traced freehand on each slice to calculate an area. The area on each slice is summed to calculate a volume. Response Evaluation Criteria in Solid Tumors 1.0 criteria was used to assess response to therapy in terms of $\mathrm{CR}$, partial response (PR), stable disease (SD) and progressive disease (PD) (33). In addition, $\mathrm{nCR}$ was defined as a decrease in tumor size of between 95 and 99\%. Disease control rate (DCR) was defined as the combination of CR, nCR, PR and SD. Overall 
Table I. Patient characteristics.

\begin{tabular}{lcrl}
\hline Variable & Subcategory & No. of patients $(\mathrm{n}=15)$ & Percentage, $\%$ \\
\hline Gender & Male & 13 & 86.67 \\
& Female & 2 & 13.33 \\
ECOG status & 0 & 10 & 66.67 \\
& 1 & 5 & 33.33 \\
Cancer status & New & 3 & 20.00 \\
& Recurrent & 12 & 80.00 \\
Cancer extent & Loco-regional & 11 & 73.33 \\
& Metastatic & 4 & 26.67 \\
Prior treatment & Radiotherapy & 13 & 86.67 \\
& Chemotherapy & 8 & 53.33 \\
p16 status & Surgery & 6 & 40.00 \\
& Positive & 3 & 20.00 \\
& Negative & 3 & 20.00 \\
\end{tabular}

ECOG, Eastern Cooperative Oncology Group.

Table II. Dosages used in the present study compared with the recommended dosages.

\begin{tabular}{|c|c|c|c|c|}
\hline \multirow[b]{2}{*}{ Drug } & \multirow[b]{2}{*}{ Recommended dose } & \multicolumn{3}{|c|}{ Dosage administered } \\
\hline & & Mean & Median & Range \\
\hline Paclitaxel & $135-175 \mathrm{mg} / \mathrm{m}^{2}$ & 73.00 & 80.00 & $40-80$ \\
\hline Cisplatin & $100 \mathrm{mg} / \mathrm{m}^{2}$ & 42.47 & 40.00 & $20-75$ \\
\hline 5-Fluorouracil & $1,000 \mathrm{mg} / \mathrm{m}^{2} /$ day for 4 days & 398.93 & 360.00 & $200-800$ \\
\hline Cetuximab & $400 \mathrm{mg} / \mathrm{m}^{2}$ then $250 \mathrm{mg} / \mathrm{m}^{2}$ & Unchanged & Unchanged & Unchanged \\
\hline Carboplatin & 5-6 AUC & 3.40 & 3.50 & $2-6$ \\
\hline Panitumumab & $9 \mathrm{mg} / \mathrm{kg}$ & 4.54 & 3.50 & $2-9$ \\
\hline Docetaxel & $75 \mathrm{mg} / \mathrm{m}^{2}$ & 78.25 & 80.00 & $70-90$ \\
\hline Nab-paclitaxel & $100 \mathrm{mg} / \mathrm{m}^{2}$ & 87.37 & 90.00 & $80-100$ \\
\hline
\end{tabular}

response rate (ORR) was defined as the combination of $\mathrm{CR}$, $\mathrm{nCR}$ and PR. A pathologic complete response (pCR) was where radiological examination revealed residual disease but pathological examination did not reveal any residual cancer. OS was defined as the interval between the beginning of the first cycle of chemotherapy to the final follow-up or death. Progression-free-survival (PFS) was defined as the time interval between initiation of chemotherapy, and documentation of progression or death from any cause or the final follow-up in surviving patients without progression. Time to tumor progression (TTP) was defined as the time between initiating chemotherapy and disease progression, not confounded by deaths. The survival data from the present study was also compared with three data sets, which used the standard dosing reported in the literature. Each of the trials, TAX323 (9), EXTREME (12) and SPECTRUM (14), used cisplatin and 5-FU with an additional third agent; docetaxel, cetuximab or panitumumab. Statistical analysis was performed using SPSS software (version 23; IBM SPSS,
Armonk, NY, USA) and the OS and PFS of the patient was measured using Kaplan-Meier estimators.

\section{Results}

Response. At the initial follow-up (mean, 64 days; 3 cycles), 2 patients achieved an nCR, 10 patients achieved a PR and 3 patients had SD, which corresponded with a $100 \%$ DCR and an $80 \%$ ORR. At the second follow-up (mean, 145 days; 6 cycles) 2 patients had succumbed to the disease and 13 patients were available for follow up. A total of 2 patients exhibited an nCR, 8 exhibited a PR, 1 patient exhibited SD, while 2 patients exhibited disease progression. These results corresponded to a DCR of $73.33 \%$ and an ORR of $66.67 \%$. At the third follow-up (mean, 217 days; 9 cycles) 1 additional patient had succumbed to the disease and 12 patients were available for follow-up. At this point 3 patients exhibited an nCR, 6 patients exhibited a PR and 3 patients exhibited progressive disease. These results corresponded to a $60 \%$ DCR and ORR. Furthermore, 
Table III. Radiological responses noted at successive follow-ups.

\begin{tabular}{|c|c|c|c|c|c|c|}
\hline \multirow[b]{2}{*}{ Radiological response } & \multicolumn{2}{|c|}{ 1st follow-up ${ }^{a}$} & \multicolumn{2}{|c|}{ 2nd follow-up ${ }^{b}$} & \multicolumn{2}{|c|}{3 rd follow-up ${ }^{c}$} \\
\hline & $\mathrm{n}=15$ & Percentage, $\%$ & $\mathrm{n}=13$ & Percentage, $\%$ & $\mathrm{n}=12$ & Percentage, $\%$ \\
\hline CR & 0 & 0.00 & 0 & 0.00 & 0 & 0.00 \\
\hline $\mathrm{nCR}$ & 2 & 13.33 & 2 & 6.67 & 3 & 20.00 \\
\hline PR & 10 & 66.67 & 8 & 53.33 & 6 & 40.00 \\
\hline SD & 3 & 20.00 & 1 & 6.67 & 0 & 0.00 \\
\hline PD & 0 & 0.00 & 2 & 13.33 & 3 & 20.00 \\
\hline $\mathrm{DCR}=\mathrm{CR}+\mathrm{nCR}+\mathrm{PR}+\mathrm{SD}$ & 15 & 100.00 & 11 & 73.33 & 9 & 60.00 \\
\hline $\mathrm{ORR}=\mathrm{CR}+\mathrm{nCR}+\mathrm{PR}$ & 12 & 80.00 & 10 & 66.67 & 9 & 60.00 \\
\hline
\end{tabular}

${ }^{a}$ Mean, 64 days; ${ }^{b}$ mean, 145 days; ${ }^{c}$ mean, 217 days. CR, complete response; nCR, near CR; PR, partial response; SD, stable disease; PD, progressive disease; DCR, disease control rate; ORR, overall response rate.

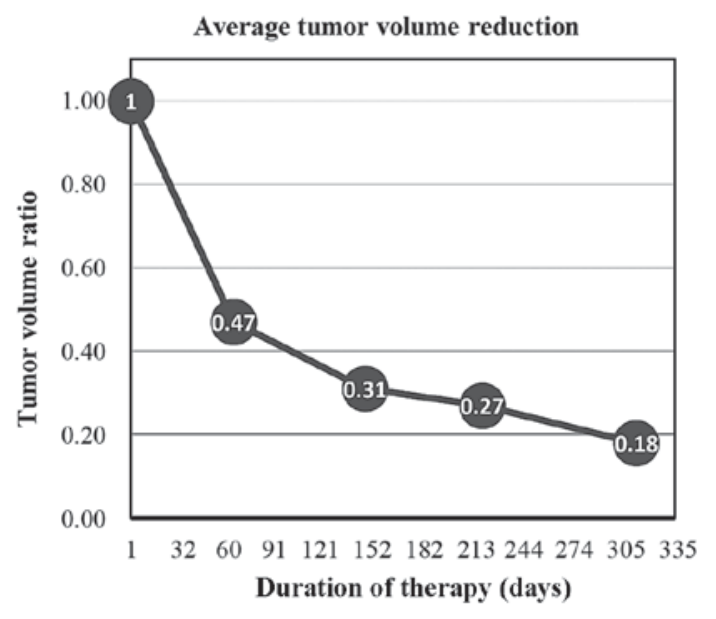

Figure 1. Average tumor volume decreased during the course of therapy. Average tumor volume was quantified using computed tomography and magnetic resonance imaging, and normalized to the tumor volume measured on the first day of treatment.

following termination of chemotherapy after $>9$ cycles, 4 patients remained disease free after $\sim 1$ year. Therefore, the increased duration of chemotherapy afforded by the decreased dosage may prolong survival in a subset of patients who otherwise had terminal disease prior to therapy. A total of 2 patients achieved an $\mathrm{nCR}$ and underwent surgical exploration after 6 cycles of chemotherapy. Although radiographically there was residual disease, no residual disease was able to be identified pathologically. Similarly, another patient underwent radiofrequency ablation of the remaining radiographic tumor deposit (lymph node) and this site was subsequently biopsied. No further tumor was identified upon pathological examination. Each of these patients exhibited a pCR, despite exhibiting a radiographical nCR or PR. Table III presents the patient radiological responses to therapy at successive follow-ups.

By measuring tumor volumes radiographically, an average reduction in tumor volume of $\sim 53, \sim 69$ and $\sim 73 \%$ after $3(n=15), 6(n=13)$ and $9(n=8)$ cycles, respectively, was observed (Fig. 1). While the majority of patients exhibited a positive response to therapy, 2 patients exhibited disease progression by the 2 nd follow-up (after between 5 and 6 cycles) and another 3 patients exhibited disease progression by the $3 \mathrm{rd}$ follow-up (after between 8 and 9 cycles). The median TTP was 6.80 months (range, 3.93-10.03 months). Kaplan-Meier estimators of survival demonstrated the median PFS to be 10.03 months and the median OS to be 15.77 months.

The survival data from the present study was also compared with three data sets, which used the standard dosing reported in the literature $(9,12,14)$. Each of the trials (TAX323, EXTREME, SPECTRUM) used cisplatin and 5-FU with an additional third agent; docetaxel, cetuximab or panitumumab. Fig. 2 presents the PFS curves of these studies, which used increased doses of the drugs used in the present study. Each of these trials reported decreased ORRs, while two trials (EXTREME, SPECTRUM) reported a decreased PFS and OS compared with the present study. Therefore, the patients in the present study exhibited an equivalent or increased survival time with decreased toxicity (increased QOL), as is presented in Tables IV and V.

Toxicity. Toxicities were graded according to the National Cancer Institute CTCAE and are listed in detail in Table VI. QOL was an important consideration in the present study. Dosages were decreased to avoid grade 3 and 4 side effects, and a low threshold was used to reduce the dosage or change the regimen based on clinical assessment. The only grade 3 hematological toxicity was neutropenia in 3 (20\%) patients with lowest absolute neutrophil counts of 580,760 and 790 cells $/ \mathrm{mm}^{3}$. The reported grade 3 toxicity symptoms or side effects were vomiting $(n=1)$ and mouth soreness/stomatitis $(n=1)$. A total of 1 patient exhibited anaphylaxis in response to cetuximab.

\section{Discussion}

The treatment of inoperable LA/R/M HNSCC is challenging due to the poor prognosis and the difficulty in achieving a balance between QOL and improved survival time. Induction chemotherapy is well-known to be a toxic regimen $(15,28)$. Ideally, regimens that offer similar response rates and reduced toxicity are a promising alternative. The results of the present 
Table IV. Comparative results of the present study with the results of previously published studies.

\begin{tabular}{|c|c|c|c|c|c|c|c|c|}
\hline Author, year & Study; dosages & $\mathrm{n}$ & Cycles & $\begin{array}{c}\text { Overall } \\
\text { response } \\
\text { rate, \% }\end{array}$ & $\begin{array}{c}\text { Disease } \\
\text { control } \\
\text { rate, } \%\end{array}$ & $\begin{array}{c}\text { Progression- } \\
\text { free survival, } \\
\text { months }\end{array}$ & $\begin{array}{c}\text { Overall } \\
\text { survival, } \\
\text { months }\end{array}$ & (Refs.) \\
\hline $\begin{array}{l}\text { Vermorken et al, } \\
2007\end{array}$ & $\begin{array}{l}\text { TAX323; } \\
\text { docetaxol, } 75 \mathrm{mg} / \mathrm{m}^{2}, \\
\text { cisplatin, } 75 \mathrm{mg} / \mathrm{m}^{2} \\
\text { and } 5-\mathrm{FU}, 750 \mathrm{mg} / \mathrm{m}^{2} / \text { day }\end{array}$ & 177 & $4^{\mathrm{a}}$ & 68 & - & 11.0 & 18.8 & (9) \\
\hline $\begin{array}{l}\text { Vermorken et al, } \\
2008\end{array}$ & $\begin{array}{l}\text { EXTREME; } \\
\text { cisplatin } 100 \mathrm{mg} / \mathrm{m}^{2} \\
\text { or carboplatin AUC 5, } \\
5 \text {-FU, } 1,000 \mathrm{mg} / \mathrm{m}^{2} / \text { day } \\
\text { and cetuximab, 400/mgm }{ }^{2} \\
\text { then } 250 \mathrm{mg} / \mathrm{m}^{2}\end{array}$ & 222 & $6^{\mathrm{a}}$ & 36 & 81 & 5.6 & 10.1 & (12) \\
\hline $\begin{array}{l}\text { Vermorken et al, } \\
2013\end{array}$ & $\begin{array}{l}\text { SPECTRUM; } \\
\text { cisplatin } 100 \mathrm{mg} / \mathrm{m}^{2}, 5-\mathrm{FU} \text {, } \\
1,000 \mathrm{mg} / \mathrm{m}^{2} / \mathrm{day} \text { and } \\
\text { panitumumab, } 9 \mathrm{mg} / \mathrm{kg}\end{array}$ & 327 & $6^{\mathrm{a}}$ & 36 & 82 & 5.8 & 11.1 & (14) \\
\hline $\begin{array}{l}\text { Bishnoi et al, } \\
2017\end{array}$ & Present study & 15 & $9^{b}$ & 80 & 100 & 10.0 & 15.8 & - \\
\hline
\end{tabular}

${ }^{\mathrm{a}}$ Maximum; ${ }^{\mathrm{b}}$ median. 5-FU, 5-fluorouracil.

\section{Comparative progression-free survival graphs}

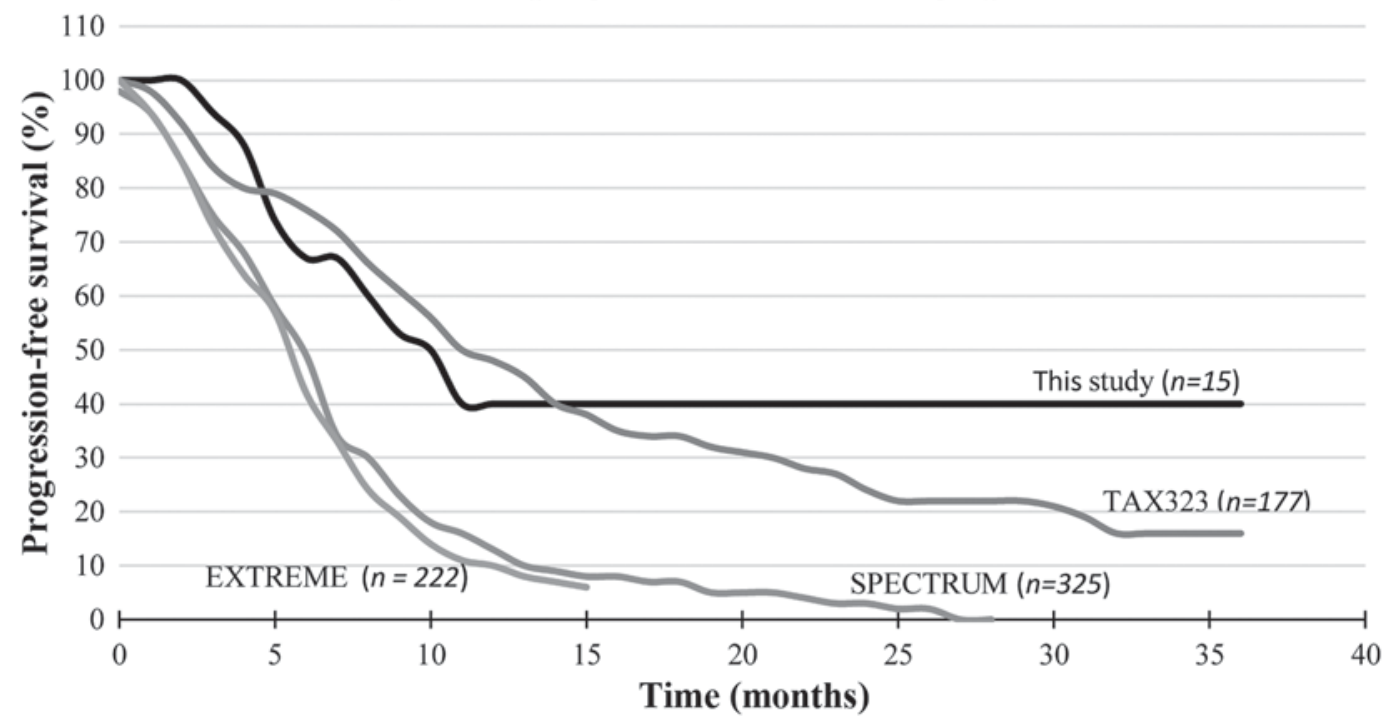

Figure 2. Comparison of patient progression-free survival rates in previously published clinical with those in the present study. The present study using decreased doses of drugs led to equivalent or increased survival rates. The progression-free survival rate at 35,15 , and 28 months was $\sim 20.0,8.0$ and $0.0 \%$ for the TAX323 (9), EXTREME (12), and SPECTRUM (14) trials, respectively, compared with $40 \%$ in the present study.

study demonstrated that an adjusted dose regimen may be used in induction chemotherapy and provide a positive ORR, while avoiding the majority of the level 3 and 4 side effects typically encountered with standard National Comprehensive Cancer Network guideline doses (32).

Due to patient requests, chemotherapy was administered with the primary priority of improving QOL despite a potential decrease in response and survival time. However, following the treatment of several patients, initial clinical responses were observed after between 1 and 2 cycles, and patients reported reduced pain, a decreased requirement to take pain medication, a reduction in palpable tumor size. and an increased ability to swallow or open their mouth. These initial clinical responses were verified radiographically with a $\leq 95 \%$ response noted at the first radiographic follow-up (after 3 rd cycle). These clinical and radiographical responses were noted prior to increasing the doses of each drug, indicating that these decreased doses were effective. Therefore, these results challenge the axiom 
Table V. Comparative toxicity between the landmark studies TAX323 (9), EXTREME (12) and SPECTRUM (14), and the present study.

Total number of events (\%)

\begin{tabular}{lcccc}
\cline { 2 - 4 } Toxicity & Present study $\mathrm{n}=15$ & TAX323 $\mathrm{n}=173$ & EXTREME $\mathrm{n}=219$ & SPECTRUM $\mathrm{n}=325$ \\
\hline Neutropenia & $3(20.0)$ & $133(76.9)$ & $49(22.0)$ & $103(32.0)$ \\
Anemia & 0 & $16(9.2)$ & $29(13.0)$ & $39(12.0)$ \\
Thrombocytopenia & 0 & $9(5.2)$ & $24(11.0)$ & $21(6.0)$ \\
Acute kidney injury & 0 & - & - & $10(3.0)$ \\
Nausea & 0 & $1(0.6)$ & - & - \\
Vomiting & $1(6.7)$ & $1(0.6)$ & $12(5.0)$ & - \\
Diarrhea & 0 & $5(2.9)$ & - & $15(5.0)$ \\
Anorexia & 0 & $1(0.6)$ & - & - \\
Stomatitis & $1(6.7)$ & $1(4.6)$ & - & - \\
Neurotoxicity & 0 & $1(0.6)$ & $11(5.0)$ & - \\
Lethargy & 0 & $5(2.9)$ & & - \\
\hline
\end{tabular}

that increased doses are associated with improved response. This axiom may be true in the absence of side effects; however, the development of severe side effects frequently prevents the benefits of increased dosing from every being realized (16). Therefore, an optimal balance between clinical response and the development of side effects should be reached in order to maximize the clinical outcome of a given patient.

As the toxicities were effectively minimized over the duration of therapy, the true effectiveness of these drug regimens was observed. Chemotherapy using standard doses frequently has to be terminated due to patient request, despite dose adjustment potentially having been able to alleviate the resultant toxicities. The identical endpoint dose may have been reached using standard dosing; however, using decreased starting doses appears to allow an increased number of patients to reach their optimal dosing. Therefore, the benefit of this approach may not be from the final dosing used (decreased final dose), but the avoidance of various toxicities. These results highlight a key point in the treatment of patients, their overall lack of tolerance to moderate or high toxicity. Therefore, these results emphasize that a key goal of the therapeutic approach is to avoid toxicity to increase patient moral and willingness to proceed with chemotherapy. This is verified by the overall increased duration of therapy tolerated by patients following this regimen, with the mean duration of chemotherapy being 205 days (range, 69-438 days). A subset of patients $(n=5)$, who were treated with chemotherapy for $\sim 10$ months (mean, 296 days), remains alive and exhibits an $\mathrm{nCR}(\mathrm{n}=2)$ or $\mathrm{PR}$ $(n=3) \sim 1$ year post the termination of chemotherapy (mean, 399 days). This suggests that certain patients may achieve long term survival following increased treatment duration. This is further supported by the 2 patients, who exhibited no pathologic disease at the primary site despite exhibiting partial responses radiographically.

As the results of the present study support the administration of a minimally toxic regimen in an effort to maximize QOL and increase the duration of treatment, the most effective drugs or combination for this approach should be investigated.
Previously, various monotherapies have been used, which produced response rates of between 10 and $25 \%$, and median survival times of between 6 and 8 months, and therapies using two drug combinations did not exhibit notable benefits except an improvement in the ORR (5). Due to the improved ORR using a platinum-based antineoplastic and 5-FU regimen, it was the standard care regimen until the addition of cetuximab exhibited significantly improved survival and response rates (12). A similar study using panitumumab exhibited an improved PFS rate but not an improved OS rate (14). Currently, a four-drug combination regimen of taxane, 5-FU, platinum-based antineoplastics and cetuximab is being examined (34), and using a decreased dose approach may allow for improved evaluation of effectiveness. However, using the now standard three-drug regimen at a decreased dose, a median PFS time of 10.03 months, an OS time of 15.77 months, a DCR of $100 \%$ and an ORR of $80 \%$ was observed after 3 cycles. The toxicity profile in the present study was benign with infrequent grade 3 toxicities. Similar and improved results with improved QOL were achieved in the present study compared with previous studies $(9,12,14)$. The present study is limited by the small sample size, and requires validation using a larger sample size and prospective study, prior to generalization.

In the present study, patients with inoperable LA/R/M HNSCC were treated with decreased doses of chemotherapeutics in order to avoid toxicity and maximize QOL. This approach produced an increased PFS and OS time compared with other standard regimens, and avoided commonly observed level 3 and 4 toxicities. In a subset of patients, a notably increased DFS time of $>12$ months was observed, indicating a potential role for this approach in the treatment of cancer.

\section{Acknowledgements}

The authors of the present study would like to thank Ms. Melissa Reisman (Department of Medicine, University of Florida, Gainesville, FL, USA) for her contribution to the editing of the present study. 
Table VI. Toxicity and adverse effects were graded according to the National Cancer Institute Common Terminology Criteria for Adverse Events (version 3.0).

\begin{tabular}{|c|c|c|c|}
\hline Toxicity & Toxicity grade & $\mathrm{n}=15$ & Percentage, $\%$ \\
\hline \multirow[t]{4}{*}{ Anemia } & 1 & 6 & 40.00 \\
\hline & 2 & 8 & 53.33 \\
\hline & 3 & 0 & 0.00 \\
\hline & 4 & 0 & 0.00 \\
\hline \multirow[t]{4}{*}{ Thrombocytopenia } & 1 & 4 & 26.67 \\
\hline & 2 & 5 & 33.33 \\
\hline & 3 & 0 & 0.00 \\
\hline & 4 & 0 & 0.00 \\
\hline \multirow[t]{4}{*}{ Neutropenia } & 1 & 5 & 33.33 \\
\hline & 2 & 1 & 6.67 \\
\hline & 3 & 3 & 20.00 \\
\hline & 4 & 0 & 0.00 \\
\hline \multirow[t]{4}{*}{ Acute kidney injury (creatinine elevation) } & 1 & 2 & 13.33 \\
\hline & 2 & 1 & 6.67 \\
\hline & 3 & 0 & 0.00 \\
\hline & 4 & 0 & 0.00 \\
\hline \multirow[t]{4}{*}{ Vomiting } & 1 & 2 & 13.33 \\
\hline & 2 & 0 & 0.00 \\
\hline & 3 & 1 & 6.67 \\
\hline & 4 & 0 & 0.00 \\
\hline \multirow[t]{4}{*}{ Diarrhea } & 1 & 1 & 6.67 \\
\hline & 2 & 0 & 0.00 \\
\hline & 3 & 0 & 0.00 \\
\hline & 4 & 0 & 0.00 \\
\hline \multirow[t]{4}{*}{ Anorexia } & 1 & 2 & 13.33 \\
\hline & 2 & 1 & 6.67 \\
\hline & 3 & 0 & 0.00 \\
\hline & 4 & 0 & 0.00 \\
\hline \multirow[t]{4}{*}{ Stomatitis (mouth soreness) } & 1 & 5 & 33.33 \\
\hline & 2 & 5 & 33.33 \\
\hline & 3 & 1 & 6.67 \\
\hline & 4 & 0 & 0.00 \\
\hline \multirow[t]{4}{*}{ Neurotoxicity } & 1 & 1 & 6.67 \\
\hline & 2 & 2 & 13.33 \\
\hline & 3 & 0 & 0.00 \\
\hline & 4 & 0 & 0.00 \\
\hline \multirow[t]{4}{*}{ Lethargy } & 1 & 7 & 46.67 \\
\hline & 2 & 4 & 26.67 \\
\hline & 3 & 0 & 0.00 \\
\hline & 4 & 0 & 0.00 \\
\hline \multirow[t]{4}{*}{ Rash } & 1 & 7 & 46.67 \\
\hline & 2 & 2 & 13.33 \\
\hline & 3 & 0 & 0.00 \\
\hline & 4 & 0 & 0.00 \\
\hline \multirow[t]{4}{*}{ Conjunctivitis } & 1 & 2 & 13.33 \\
\hline & 2 & 1 & 6.67 \\
\hline & 3 & 0 & 0.00 \\
\hline & 4 & 0 & 0.00 \\
\hline
\end{tabular}




\section{References}

1. Siegel RL, Miller KD and Jemal A: Cancer statistics, 2016. CA Cancer J Clin 66: 7-30, 2016

2. Digonnet A, Hamoir M, Andry G, Haigentz M Jr, Takes RP, Silver CE, Hartl DM, Strojan P, Rinaldo A, de Bree R, et al: Post-therapeutic surveillance strategies in head and neck squamous cell carcinoma. Eur Arch Otorhinolaryngol 270: 1569, 2013

3. Sanderson RJ and Ironside JAD: Squamous cell carcinomas of the head and neck. BMJ 325: 822-827, 2002.

4. Pulte D and Brenner H: Changes in survival in head and neck cancers in the Late 20th and early 21st century: A period analysis. Oncologist 15: 994-1001, 2010.

5. Molin Y and Fayette J: Current chemotherapies for recurrent/metastatic head and neck cancer. Anticancer Drugs 22: 621-625, 2011.

6. Carvalho AL, Nishimoto IN, Califano JA and Kowalski LP: Trends in incidence and prognosis for head and neck cancer in the United States: A site-specific analysis of the SEER database. Int J Cancer 114: 806-816, 2005.

7. Péron J, Polivka V, Chabaud S, Poupart M, Ceruse P, Ramade A, Girodet D, Zrounba P and Fayette J: An effective and well-tolerated strategy in recurrent and/or metastatic head and neck cancer: Successive lines of active chemotherapeutic agents. BMC Cancer 14: 504, 2014.

8. Posner MR: Docetaxel in squamous cell cancer of the head and neck. Anticancer Drugs 12 (Suppl 1): S21-S24, 2001.

9. Vermorken JB, Remenar E, van Herpen C, Gorlia T, Mesia R, Degardin M, Stewart JS, Jelic S, Betka J, Preiss JH, et al: Cisplatin, fluorouracil, and docetaxel in unresectable head and neck cancer. N Engl J Med 357: 1695-1704, 2007.

10. Blanchard P, Bourhis J, Lacas B, Posner MR, Vermorken JB, Hernandez JJ, Bourredjem A, Calais G, Paccagnella A, Hitt R, et al: Taxane-cisplatin-fluorouracil as induction chemotherapy in locally advanced head and neck cancers: An individual patient data meta-analysis of the meta-analysis of chemotherapy in head and neck cancer group. J Clin Oncol 31: 2854-2860, 2013

11. Guigay J, Fayette J, Dillies AF, Sire C, Kerger JN, Tennevet I, Machiels JP, Zanetta S, Pointreau Y, Bozec Le Moal L, et al: Cetuximab, docetaxel, and cisplatin as first-line treatment in patients with recurrent or metastatic head and neck squamous cell carcinoma: A multicenter, phase II GORTEC study. Ann Oncol 26: 1941-1947, 2015

12. Vermorken JB, Mesia R, Rivera F, Remenar E, Kawecki A, Rottey S, Erfan J, Zabolotnyy D, Kienzer HR, Cupissol D, et al: Platinum-based chemotherapy plus cetuximab in head and neck cancer. N Engl J Med 359: 1116-1127, 2008.

13. de Mello RA, Gerós S, Alves MP, Moreira F, Avezedo I and Dinis J: Cetuximab plus platinum-based chemotherapy in head and neck squamous cell carcinoma: A retrospective study in a single comprehensive European cancer institution. PLoS One 9: e86697, 2014.

14. Vermorken JB, Stöhlmacher-Williams J, Davidenko I, Licitra L, Winquist E, Villanueva C, Foa P, Rottey S, Skladowski K, Tahara M, et al: Cisplatin and fluorouracil with or without panitumumab in patients with recurrent or metastatic squamous-cell carcinoma of the head and neck (SPECTRUM): An open-label phase 3 randomised trial. Lancet Oncol 14: 697-710, 2013.

15. Goldstein NE, Genden E and Morrison RS: Palliative care for patients with head and neck cancer: 'I would like a quick return to a normal lifestyle'. JAMA 299: 1818-1825, 2008.

16. Perri F, Muto P, Argenone A, Ionna F, Longo F, Fulciniti F, Sandomenico F, Daponte A and Caponigro F: Induction chemotherapy with docetaxel, cisplatin and capecitabine, followed by combined cetuximab and radiotherapy in patients with locally advanced inoperable squamous cell carcinoma of the head and neck: A phase I-II study. Oncology 84: 251-254, 2013.

17. De Felice F, Musio D and Tombolini V: Head and neck cancer: Metronomic chemotherapy. BMC Cancer 15: 677, 2015.

18. Rangaraju RR, Sharma JB, Dewan AK, Anand AK, Sheh R, Jena A and Chaturvedi AK: Palliative weekly chemotherapy along with cetuximab in recurrent and metastatic head and neck cancers: A retrospective analysis. Indian J Cancer 49: 1-5, 2012.

19. Yossi S, Linot B, Peyraga G, Breheret R, Laccourreye L and Capitain O: Feasibility and safety of dose-dense modified docetaxel-cisplatin or carboplatin and 5-fluorouracil regimen (mTPF) in locally advanced or metastatic head and neck cancers: A retrospective monocentric study. Int J Clin Oncol 20 : 1086-1092, 2015.
20. Schena M, Barone C, Birocco N, Dongiovanni D, Numico G, Colantonio I and Bertetto O: Weekly cisplatin paclitaxel and continuous infusion fluorouracil in patients with recurrent and/or metastatic head and neck squamous cell carcinoma: A phase II study. Cancer Chemother Pharmacol 55: 271-276, 2005.

21. Guntinas-Lichius O, Appenrodt S, Veelken F and Krug B: Phase II study of weekly docetaxel and cisplatin in patients with advanced recurrent and metastatic head and neck cancer. Laryngoscope 116: 613-618, 2006.

22. Cho H, Nishiike S, Yamamoto Y, Takenaka Y, Nakahara S, Yasui T, Hanamoto A and Inohara H: Docetaxel, cisplatin, and fluorouracil for patients with inoperable recurrent or metastatic head and neck squamous cell carcinoma. Auris Nasus Larynx 42: 396-400, 2015

23. Lin JT, Lai GM, Chang TH, Liu MT, Bi CP, Wang JW and Chen MK: Chemotherapy with modified docetaxel, cisplatin, and 5 -fluorouracil in patients with metastatic head and neck cancer. Adv Ther 29: 71-77, 2012.

24. Forastiere AA, Takasugi BJ, Baker SR, Wolf GT and Kudla-Hatch V: High-dose cisplatin in advanced head and neck cancer. Cancer Chemother Pharmacol 19: 155-158, 1987.

25. Mantovani G, Ghiani M, Lai P, Maccio A, Dessi D, Succu G, Massa D, Curreli L, Mulas C, Esu S, et al: Clinical evaluation of two dosages and schedules of ifosfamide in combination with cisplatin in neo-adjuvant chemotherapy of patients with advanced (stage III-IV) head and neck squamous cell carcinoma: A phase II randomized study. Oncol Rep 5: 1499-1505, 1998.

26. Dhawan A, Ruwali M, Pant MC, Rahman Q and Parmar D: Association of genetic variability in enzymes metabolizing chemotherapeutic agents with treatment response in head and neck cancer cases. Asia Pac J Clin Oncol: Jan 21, 2016 (Epub ahead of print). doi: 10.1111/ajco.12446.

27. Bussmann L, Busch CJ, Lörincz BB, Rieckmann T, Block A and Knecht R: Perspectives in chemosensitivity and chemoresistance assays and their implementation in head and neck cancer. Eur Arch Otorhinolaryngol 273: 4073-4080, 2016.

28. Ko EC, Genden EM, Misiukiewicz K, Som PM, Kostakoglu L, Chen CT, Packer S and Kao J: Toxicity profile and clinical outcomes in locally advanced head and neck cancer patients treated with induction chemotherapy prior to concurrent chemoradiation. Oncol Rep 27: 467-474, 2012.

29. Posner MR, Hershock DM, Blajman CR, Mickiewicz E, Winquist E, Gorbounova V, Tjulandin S, Shin DM, Cullen K, Ervin TJ, et al: Cisplatin and fluorouracil alone or with docetaxel in head and neck cancer. N Engl J Med 357: 1705-1715, 2007.

30. Pointreau Y, Garaud P, Chapet S, Sire C, Tuchais C, Tortochaux J, Faivre S, Guerrif S, Alfonsi M and Calais G: Randomized trial of induction chemotherapy with cisplatin and 5-fluorouracil with or without docetaxel for larynx preservation. J Natl Cancer Inst 101: 498-506, 2009.

31. Oken MM, Creech RH, Tormey DC, Horton J, Davis TE, McFadden ET and Carbone PP: Toxicity and response criteria of the Eastern Cooperative Oncology Group. Am J Clin Oncol 5: 649-655, 1982.

32. Trotti A, Colevas AD, Setser A, Rusch V, Jaques D, Budach V, Langer C, Murphy B, Cumberlin R, Coleman CN and Rubin P: CTCAE v3.0: Development of a comprehensive grading system for the adverse effects of cancer treatment. Semin Radiat Oncol 13: 176-181, 2003.

33. Therasse P, Arbuck SG, Eisenhauer EA, Wanders J, Kaplan RS, Rubinstein L, Verweij J, Van Glabbeke M, van Oosterom AT, Christian MC and Gwyther SG: New guidelines to evaluate the response to treatment in solid tumors. European organization for research and treatment of cancer, national cancer institute of the United states, national cancer institute of Canada. J Natl Cancer Inst 92: 205-216, 2000.

34. Mesía R, Vázquez S, Grau JJ, García-Sáenz JA, Lozano A, García C, Carles J, Irigoyen A, Mañós M, García-Paredes B, et al: A Phase 2 open label, single-arm trial to evaluate the combination of cetuximab plus taxotere, cisplatin, and 5-flurouracil as an induction regimen in patients with unresectable squamous cell carcinoma of the head and neck. Int J Radiat Oncol Biol Phys 94: 289-296, 2016. 